\title{
Factors Contributing to Post Extubation Dysphagia in Critically Ill Patients
}

\author{
Elham Ashraf Mohamed Abdalla, Clinical Instructor \\ Critical Care and Emergency Nursing, Faculty of Nursing, Alexandria University
}

Nadia Taha Mohamed Ahmed, Professor

Critical Care and Emergency Nursing, Faculty of Nursing, Alexandria University

Fatma Refaat Abd El-Fattah Ahmed, Lecturer

Critical Care and Emergency Nursing, Faculty of Nursing, Alexandria University

Hany Samir Assaad, Lecturer

Critical Care Medicine, Faculty of Medicine, Alexandria University

\begin{abstract}
Critically care nurses play an important role to investigate and early detect suspected complications from the intubation process such as post-extubation dysphagia. Post-extubation dysphagia has negative consequences which can be classified into physiological such as malnutrition and/or dehydration, chocking, chest infection and aspiration pneumonia, in addition to psychological, and economic consequences as post-extubation dysphagia could increase the consumption of supplies, human resources, workload and the overall cost of care. There are many factors that contribute to the development of post-extubation dysphagia, which include: physiological changes related factors; age, pathological related factors; initial diagnosis and comorbidies and therapeutic related factors; presence of tracheal and gastric tube, in addition to some medications that may lead to dysphagia. Objective: Identify factors contributing to post-extubation dysphagia in critically ill patients. Setting: This study was conducted in the General Medical ICUs namely; Casualty unit (unit I), (unit III) and Continuous Renal Replacement Therapy at the Alexandria Main University Hospital (AMUH). In addition to Almoassat General ICU. Subjects: A convenience sample of 50 adult intubated critically ill patients. Tools: Two tools were used for data collection: "Factors Contributing to Post-extubation Dysphagia Assessment" and "Gugging Swallowing Screen”. Results: The differences between the studied patients according to the occurrence of post-extubation dysphagia at first 6hrs compared to after 12hrs and after 24 hrs was statistically significant $(p=<0.001)$. The duration of mechanical ventilation was the only significant risk factor to post-extubation dysphagia after 24 hrs according to the binary logistic regression analysis. Conclusion: All the studied patients developed post-extubation dysphagia by the first 6 hrs of extubation. The severity of post-extubation dysphagia varied between mild, moderate and severe. Critically ill patients were highly susceptible for exposure of multiple iatrogenic factors which can contribute to post-extubation dysphagia during ICU stay. The only significant risk factor to post-extubation dysphagia after 24 hrs was the duration of mechanical ventilation. Recommendations: Critical care nurses should be continuously monitor the intubated critically ill patients who are risky to develop post extubation dysphagia, and continuous in-serve training programs for CCNs in the ICUs.
\end{abstract}

$\underline{\text { Keywords: }}$ Critical illness; Dysphagia; Nursing care; Post-extubation dysphagia.

\section{Introduction}

Post extubation dysphagia can be occurred in critically ill patients especially in post extubation period related to prolonged mechanical ventilation, more than $50 \%$ of patients who have PED intubated for $48 \mathrm{hrs}$ or longer ${ }^{(1,2)}$.
Around $60 \%$ of critical ill patients admitted to ICU requiring endotracheal intubation as mean to maintain open-air way and deliver invasive mechanical ventilation. Endotracheal intubation as a process is used to maintain a patent, protected airway; and to support ventilation for patients who are unable to breathe adequately on their own $^{(3,4)}$. 
Endotracheal tube intubation had direct contact with structure of airway which lead to mucosal lesions this may be related to traumatic causes during insertion, prolonged time of intubation, use of large size of tube and increase cuff pressure more than normal range ${ }^{(5-7)}$.

Swallowing is a complex process which require a specific timing and coordination of more than 25 muscles and engaging five cranial nerves ${ }^{(8)}$. Inflammation and lesion in the swallowing muscles as oral cavity, pharynx, larynx caused by tracheal tube intubation could lead to negative effect in sensitivity and local motility that lead to vocal cord ulceration and loss of tissue architecture. In addition to, impaired swallowing process which cause post extubation dysphagia (PED) ${ }^{(1)}$. Dysphagia is a subjective feeling of difficulty in making the food travel from the mouth to the stomach. The word of dysphagia comes from Greek words, dys (difficulty) and phagia (eat).

Dysphagia occurs when there is a significant lack of co-ordination between the laryngeal swallowing muscles and cricopharyngeal sphincter muscles. It is caused by two main mechanisms: Mechanical obstruction or motor dysfunction.

Mechanical obstruction causes of PED: Duration of intubation, size of the ETT and cuff pressure cause mucosal inflammation leading to loss of architecture, oropharyngeal muscle atrophy from disuse during intubation, decreased laryngeal sensation, and laryngeal injury (edema, granuloma and vocal cord paralysis), luminal (e.g., large food bolus, foreign body), intrinsic to the esophagus (e.g., inflammation, webs and rings, strictures and tumors), or extrinsic to the esophagus (e.g., enlarged thyroid or mediastinal mass, vascular compression), Moreover, motor dysfunction that cause PED may be related to defects in initiating the swallowing reflex in case of tongue paralysis, lack of saliva, lesions affecting sensory components of cranial nerves $\mathrm{X}$ and $\mathrm{XI}^{(2)}$.

PED has a negative impact on critically ill patients during their ICU stay. Consequence of PED can be classified into physiological, social \& psychological, and economic consequences.

Malnutrition they may simply not be getting enough vital nutrients for good health that lead to weight loss and decrease immune system on long term ${ }^{(9-11)}$. PED can potentially also lead to dehydration related to inadequate fluid intake it may be a risk factor for pneumonia for several reasons; it can decrease salivary flow, which promotes altered colonization of the oropharynx. In addition, it may lead to lethargy, mental confusion, and increased aspiration which makes the patient susceptible to infection by depressing the immune system ${ }^{(12)}$.

Other complications such as coughing and choking are the most distressing aspects of PED consequences. The absence of coughing or chocking during the ingestion of liquids immediately after extubation is a sign of a suspected laryngeal penetration, with inhibition of the larynx sensory abilities $^{(13)}$.

In addition, aspiration could happen when food, drink or saliva go down the wrong way and enter the lung instead of the stomach. It is caused by impaired laryngeal closure or overflow of food or liquid retained in the pharynx mainly due to poor oral control and delay triggering of the swallowing reflex that is very dangerous because patients who aspirate are risky for serious respiratory complications such as; airway obstruction and aspiration pneumonia $^{(9,10)}$. Aspiration pneumonia was mainly thought to be infectious disease, it can occur by chronic repeated aspiration of small amount of sterile materials that induce chronic inflammation in the alveoli and promotes oropharyngeal colonization that consequently induces respiratory infections $^{(14,15)}$. 
Also, negative emotions associated with swallowing problems. It can lead to food avoidance, anxiety and depression during meal times mainly due to the feeling of food sticking in the throat or feeling that they were choking ${ }^{(16,17)}$.

As well as Marvin, Thibeault ${ }^{(18)}$, Macht, Wimbish ${ }^{(19)}$ and Macht, Wimbish ${ }^{(20)}$ concluded that the incidence of morbidity and mortality can increased with PED related to risk of aspiration, malnutrition, and so increases the length of ICU stay with low quality of life post ICU discharge ${ }^{(21)}$. Macht, Wimbish ${ }^{(19)}$ reported that PED can causing an economic burden, with increased consumption of supplies, human resources, workload and increase of the overall cost of care $^{(22-24)}$.

There are many factors that contribute to the development of PED, which include; physiological changes related factors, pathological related factors and therapeutic related factors.

Factors related to physiological changes; old age (aging) related to physiological changes of aging such as; loss of muscle mass and function, a reduction of tissue elasticity, changes of the cervical spine, reduction of saliva production, impaired dental status, reduced oral and pharyngeal sensitivity, reduced olfactory and gustatory function, and reduced compensatory capacity of the aging brain lead to increase the susceptibility to PED ${ }^{(25)}$.

PED is a highly prevalent clinical condition in female patients than male related to multi variables such as she swallow slower than male related to she have small oral and pharyngeal cavities than male and shortage esophageal sphincter ${ }^{(26)}$.

Pathological related factors: Critically ill patients admitted to ICUs with acute illness have also other associated comorbidities in addition to their initial diagnosis. Breathing and swallowing share a common pathway, they must be precisely coordinated to protect the airway. Factors that alter breathing patterns and ventilation, such as chronic respiratory diseases, may influence that precise coordination of breathing and swallowing ${ }^{(27,28)}$.

Razzaq and Sulaiman et al. (2015) reported that the incidence of PED increase approximately 1.8 times in patients complaining of cardiac diseases, the shifting of parasympathetic levels could increase the incidence of gastric reflex which induces PED $^{(26)}$.

Other chronic comorbidities; diabetes and hypertension could contribute to the occurrence of PED due to peripheral diabetic neuropathy and arterial atherosclerotic alterations of the larynx, these factors would increase mechanical damage by the cuff of $\operatorname{ETT}^{(29)}$.

The incidence of PED was highly reported to range from 51 to $84 \%$ in neurological disorders; as cerebrovascular accident patients, Parkinson's disease and Alzheimer's disease. Falsetti and Acciai ${ }^{(30)}$ found that PED occurs in more than a third of stroke patients, altering cognition, or causing the dysregulation of the swallowing reflex. In addition to, patients with chronic kidney disease are frequently distressed with neurological complications. These complications can potentially affect both the central and peripheral nervous systems associated with disturbance of the patient level of consciousness ${ }^{(31,32)}$.

In relation to therapeutic related factors, PED have been reported in $14 \%$ to $83 \%$ of adult patients needing to prolonged mechanical ventilation. Tracheal tube is a foreign object that had direct contact with airway structures causing mucosal lesions, mainly due to traumatic and prolonged intubations. The use of large-size tubes and high cuff pressure (especially above $25 \mathrm{~cm}$ $\mathrm{H}_{2} \mathrm{O}$ ) increase the risk of mucosal injury $^{(29,33)}$.

Gastric tube is a foreign object that crosses the entire pathway of a food bolus travels during all three stages of swallowing from the oral cavity through the pharynx and in to the esophagus with a corresponding 
prior assumption of negative impact on safe and efficient swallowing process ${ }^{(34)}$.

Many medications can induce PED by affecting smooth and striated muscle via increasing the sensitivity of mucosa resulting in swallowing difficulty, there are two different ways; firstly, there is the adverse effect due to consequences of pharmacological action such as dysphagia induced by antibiotics as well as immunosuppressive, anti-cancer agents and medication that depress CNS that may cause muscle wasting or damage to the esophagus. Secondly, there is the direct effect of medications irritating the mucosa. Medications with a $\mathrm{pH}$ less than 3 (such as doxycycline and tetracycline) and nonsteroidal anti-inflammatory drug as well as certain slow-release anticholinergic dosage medications were more caustic resulting in moderate and severe injuries of the esophageal muscles ${ }^{(35,36)}$.

Management of post extubation dysphagia: prevention of the hospitalacquired complications is an important element to ensure patient safety. Critical care nurses advocate for patients' safety, so nurses have an important role to prevent such complications as well as early diagnosis to permit early intervention and treatment of PED. Critical care nurses' role starting from patients' admission through early identification of risk groups and prevention of PED to minimize the associated complications and throughout treatment of the problem. Thus, critical care nurses assigned to intubated patients should use dysphagia-screening tools to early assess presence of dysphagia and to identify factors that could contribute to PED development. For patients who pass the dysphagia screen and are able to eat and drink as usual, appropriate daily intake of fluid and food should be monitored ${ }^{(37,38)}$.

Post extubation dysphagia can be diagnosed either through clinical noninstrumentally evaluation tool and/or instrumental evaluation tool. Clinical noninstrumentally evaluation tools are noninvasive tools, low cost, fast, require few resources and supplies, easy to use such as; Bed side swallowing evaluation (BSE) and Gugging swallowing screening. Instrumental evaluation tools are invasive procedure required trained person and supplies they are done to classify underlying physiological abnormalities and anatomical problem leading to PED; Video fluoroscopic swallowing study (VFSS) and Fiberoptic endoscopic evaluation of swallowing (FEES) remain the gold standers for instrumentally diagnosed of dysphagia ${ }^{(39)}$.

The patients received treatment based on the level of severity and the pattern of PED after swallowing function assessment. Rehabilitation of swallowing disorder aimed to enable the patient to swallow safely while protecting the airway and restore oral intake. The rehabilitation program of PED conducted through two approaches: directly and indirectly. The direct approaches mean working on the swallowing of food directly by putting food in the patient's mouth and reinforce the appropriate behavior during the swallow, while the indirect approach geared towards the oromotor control improvement. The component of treatment modalities for PED include dietary texture modifications, postural changes/ compensatory maneuvers, interventions to improve swallow function, therapeutic exercises, and neuromuscular stimulation $^{(8)}$.

Critical care nurses play an important role in prevention and management of dysphagic critically ill patient who are recently extubated ${ }^{(40)}$.

Based on these assessments, $\mathrm{CCNs}$ can judge patient is not at risk for PED, oral intake can be initiated, which is an important psychological boost $^{(41)}$.

The patient should be upright position $45^{\circ}$ to $90^{\circ}$ degree when taking meal time, use chin tuck position when swallowing $^{(42,43)}$.

Patients who could not be orally fed continued to receive nutrition by small size nasogastric tubes with follow guide line of 
tube feeding ${ }^{(44)}$. CCNs should be alert, reviewing and continuous monitoring for several drugs mechanisms that can effect on the physiological mechanisms of the swallowing such as medication that affecting smooth and strained muscle via increasing mucosa sensitivity ${ }^{(26,45-47)}$.

Because the intubated patients have multifactorial risk for developing PED, development strategies in collaboration with physician to minimize their risk factors by encouraging small size of ETT and early extubation for patients who are mechanically ventilated and using low tidal volume ventilation with minimal used of analgesia, sedation and muscle relaxant which may impair swallowing reflex ${ }^{(48)}$.

Because of the impact of PED on the critically ill patients as well as the limited availability of diagnostic tools application in ICU, costs \& safety concerns related to prolonged time of mechanical ventilation, there is an urgent need for more studies to identify the contributing factors for PED. So, this study is conducted to identify factors contributing to PED for the critically ill patient.

\section{Aim of the Study}

This study aims to identify factors contributing to post-extubation dysphagia in critically ill patients.

\section{Research Question}

What are the factors contributing to post-extubation dysphagia in critically ill patients?

\section{Materials and Method}

\section{Materials}

Design: A descriptive research design was utilized to conduct this study.

Setting: This study was conducted in the General medical ICUs namely; Casualty unit (unit I), (unit III) and Continuous Renal Replacement Therapy at the Alexandria Main University Hospital (AMUH). In addition to Almoassat General ICU.
Subjects: A convenience sample of 50 adult intubated critically ill patients based on four ICUs admission rate over four months period was used in this study.

Inclusion criteria: Critically ill adult patients require mechanical ventilation was included in this study.

Exclusion criteria: Patients with neurologic diseases that may affect swallowing reflex, esophageal dysphagia and had been submitted to surgical procedures involving the head and neck, tracheostomatized patients were excluded from the study.

Tools: Two tools were used in this study for data collection:

Tool I: Factors Contributing to PostExtubation Dysphagia Assessment

This tool was developed by the researcher after reviewing the relevant literature ${ }^{(14-16)}$ to identify risk factors for post-extubation dysphagia. It consists of two parts:

Part I: Demographic and clinical data record: This part includes demographic data such as age, sex and clinical data such as admission medical diagnosis, comorbidities, current intake of drugs (sedatives), presence of feeding tube, reasons of ventilation if present, duration of mechanical ventilation, consciousness level using Glasgow coma scale (GCS), cognitive status, and acute physiological and chronic health evaluation II (APACHE II) score. These parameters were recorded by the researcher in the assessment record.

Part II: Tracheal intubation related data: This part include data such as size of tracheal tube, reasons of tracheal intubation, duration of tracheal tube, occurrence of reintubation, cuff pressure, and tracheal tube received care. These parameters were recorded by the researcher in an assessment record.

Tool II: Gugging Swallowing Screen $\underline{\underline{\text { GUSS) }}}$ 
This tool was adopted from ${ }^{(49)}$. It was used to identify alterations of the swallowing process. It also characterizes the clinical signs that are suggestive of aspiration, and the severity of dysphagia. It consists of two parts; indirect and direct swallowing test items. Indirect swallowing test items include vigilance, cough and/or throat clearing, saliva swallow (swallowing successful, drooling, voice change). Direct swallowing test items include deglutition, cough (involuntary), drooling, voice change. The researcher was follow the clinical rationale proposed in each item of the GUSS. It was scored using a dichotomous scale of Yes and No. Total score of GUSS is equal 20; sever dysphagia (0-9); moderate dysphagia (10-14); Slight dysphagia (15-19) and no dysphagia (20).

\section{Method}

- An official letter from the Faculty of Nursing was sent to appropriate authorities in Alexandria Main University Hospital and a permission to conduct the study with explanation of the aim of the study was obtained.

- Tool one was developed by the researcher after reviewing the related literature ${ }^{(50-54)}$ and tool two was adopted from Trap (2007).

- The Tools were submitted to a jury of experts in the field of study to assess content validity and modifications were done accordingly.

- Reliability of the two tools was done before conducting the study using the Cronbach's alpha test and the test value were 0.801 and 0.984 respectively.

- A pilot study was conducted on 5 patients to assess the feasibility of the study and applicability of the tools and no modifications were done and these patients were excluded from the study subjects.

- Data were collected by the researcher during approximately (four months) starting from the beginning of February 2017 till the end of May.

- Data collection was done as follows:

- Newly admitted intubated patients were included in the study according to the previously mentioned exclusion criteria. The patients demographic data, clinical data such as admission medical diagnosis, co-morbidities, APACHE II, medication that may lead to dysphagia were recorded up on admission. Presence of feeding tube, site and size was recorded by the researcher. Glasgow coma scale (GCS) and CAM-ICU score were calculated for each patient post extubation and before performing Guss screen test to assess patients with impaired level of consciousness and cognitive status using part I of tool one. Moreover, reasons of ventilation if present, duration of mechanical ventilation in days were recorded using part I of tool I on a daily basis and till the time of extubation.

- In addition, reasons of tracheal intubation and size of tracheal tube were recorded upon intubation, duration of tracheal tube was calculated and recorded, Cuff pressures were observed at morning and evening shifts from the admission and till the time of extubation. Also, the occurrence of re-intubation and its frequency were recorded. Tracheal tube received care were observed by the researcher and recorded regularly from intubation till time of extubation using a scale of done and not done.

\section{- Gugging Swallowing Screen (GUSS)}

- Gugging Swallowing Screen was done by the researcher to assess the occurrence of dysphagia at 
different time intervals; the first time after 6 hours post extubation, the second time 12 hours post extubation and the third time after 24 hours post extubation to determine the presence of dysphagia, its severity and the risk of aspiration.

- The GUSS consists of two tests; the preliminary assessment or indirect swallowing test (test 1) and the direct swallowing test (test 2), which consists of 3 subtests, these subtests were performed sequentially. Indirect swallowing test items include vigilance, cough and/or throat clearing, saliva swallow (swallowing successful, drooling, voice change). Direct swallowing test this would include administered of semi-solid, water and bread with four distinct signs that were being assessed for deglutition, coughing, drooling and voice change. Whether the patient was able to pass this final stage would determine whether they then able to tolerate a free $\operatorname{diet}^{(55,56)}$.

- Each subtest has a maximum 5 points which can be reached. The highest total score was twenty points that denotes normal swallowing ability without aspiration risk. In which total 4 levels of severity can be determined:

- 0-9 Points: severe dysphagia and high risk for aspiration;

- 10-14 Points: moderate dysphagia and moderate risk of aspiration;

- 15-19 Points: mild dysphagia with low risk of aspiration;

- 20 Points: normal swallowing ability;
For each level of severity different diet recommendations are given.

\section{Ethical considerations:}

- Written informed consent will be obtained from patients' witnesses. It will include the aim of the study, potential benefits, risks and discomforts from participation and the right to refuse to participate in the study will be emphasized to subjects.

- Patients' privacy, anonymity and confidentiality of the collected data will be maintained during implementation of the study.

\section{Statistical Analysis}

Data were fed to the computer and analyzed using IBM SPSS software package version 20.0. (Armonk, NY: IBM Corp) Qualitative data were described using number and percent. Quantitative data were described using range (minimum and maximum), mean, standard deviation. Significance of the obtained results was judged at the $5 \%$ level.

\section{Results}

\section{Part I: Descriptive of the studied sample:}

Table (1) presents the frequency distribution of the studied critically ill patients in relation to demographic data. It was observed that $68 \%$ of the studied patients aged between 51-60 years old. Whereas the minority of the studied patients (10\%) aged between 18-30 years old. Regarding to sex, the majority of the studied patients (64\%) were male.

Table (2) shows frequency distribution of studied critically ill patients according to occurrence of dysphagia at different time intervals. There were statistically significant differences between occurrences of dysphagia at first $6 \mathrm{hrs}$ post extubation compared to after $12 \mathrm{hrs}$ and after $24 \mathrm{hrs}$ of studied patients post extubation $(\mathrm{p}=<0.001)$.

Figure (1) shows that $4 \%, 18 \%$ of studied critically ill patients had been 
returned to mechanical ventilation after first $12 \mathrm{hrs}$ and $24 \mathrm{hrs}$ respectively.

Table (3) illustrates the frequency distribution of the studied critically ill patients according to their clinical data. This table reveals that the mean of APACHE II score, was 22.58 \pm 7.12 . Regarding occurrence of delirium, it was noticed that all of the studied patients had no delirium $(100 \%)$. In relation to LOC, it was observed that all the studied patients were conscious $(100 \%)$. Lastly, regarding the length of ICU stay, it can be observed from this table that $48 \%$ of the studied patients stayed in ICU for 7-14 days.

Table (4) reveals that there was statistically significant difference between the occurrence of PED for the studied patients within first $24 \mathrm{hrs}$ and demographic data. It was found that there was statistically significant difference between the occurrence of PED for the studied patients within first $24 \mathrm{hrs}$ and studied male patients $(\mathrm{p}=0.009)$. Moreover, it was noticed that there was no statistically significant difference between occurrence of PED and age $(\mathrm{p}=0.145)$.

Table (5) reveals that there was statistically significant difference between occurrence of PED for studied patients and length of ICU stay, APACHE II score, $(\mathrm{p}=0.001), \quad(\mathrm{p}=0.028) \quad$ respectively. Moreover, it was noticed that there was no statistical significant difference between occurrence of PED and CAM-ICU, LOC using (GCS).

Table (6) showed binary logistic regression analysis for possible risk factors that affecting occurrence of PED within first $24 \mathrm{hrs}$. Duration of mechanical ventilation was the only significant risk factors. $(\mathrm{OR}=28.207,95 \% \mathrm{CI}=2.31 \mathrm{TO} 341.20)$.

\section{Discussion}

Regarding age, the current study revealed that more than half of the patients were aged between 51-60 years old. This may related to older patients are more likely to developed PED, this may related to physiological changes of aging such as; loss of muscle mass function, reduce tissue elasticity of swallowing muscle, reduction of salivary production, impaired dental status in addition to, reduced olfactory and gustatory function. This Finding is supported by other studies ${ }^{(13,29,57,58)}$ which found that most of risk factors that predispose to PED include an older age patients. Changes in the swallowing physiology, such as loss of muscle mass and the elastic properties of connective tissue, may result in loss of muscle strength and mobility. These changes can have a negative impact on swallowing efficiency and on airways protection. The age-related atrophy of the pharyngeal and laryngeal soft tissues may also considered a contributing factor for swallowing alterations.

As regards to gender, the present study revealed that the majority of the studied patients were males. This may related to most of the male patients have usually smoking which lead to negative impact on swallowing muscles and intubated related to COPD diagnosis which lead to desynchronization between breathing and swallowing. This finding is congruent with study done by Park et al. (2017) ${ }^{(57)}$, which found that the majority of the studied dysphagic critically ill patients were male. This result is opposed with study done by Mouawad and Ahluwalia $(2017)^{(58)}$, who found that female gender was associated with developed of PED than male patient related to multiple variable such as swallow slower than male related to she have small oral and pharyngeal cavities than male and shortage esophageal sphincter.

The current study showed that the majority of the studied critically ill patients had PED improved over time of 6, 12, 24 hours. This may explained by lack of nurses' awareness about factors contributing to PED for intubated critically ill patients and how to prevent it and early signs and symptoms of PED in additions to, decrease awareness about swallowing rehabilitation program 
post extubation. This finding is in line with ${ }^{(18)}$ who found that the majority of sample had improvement in swallow function between 4 and $24 \mathrm{hrs}$ following extubation. This finding is in contrast to another study ${ }^{(13)}$ which found that more than two third of patients who were initially diagnosed with severe or moderate dysphagia persisted with this condition after hospital discharge. Also, Brodsky et al. $(2017)^{(59)}$ who found that one-third of orally intubated patients have dysphagia symptoms that persist beyond hospital discharge.

Regarding clinical data of studied patients, the results of current study revealed that there were statistically significance between APACHEII score on admission and occurrence of PED. This finding is in line with See et al. (2016) ${ }^{(40)}$ who found that there was a statistical significant difference between APACHEII score and swallowing problem post extubation. This finding is in contrast with other studies ${ }^{(33,59)}$ which found that there was no statistically relation between APACHEII score and occurrence of dysphagia.

Regarding duration of ICU stay, the results of current study revealed that the duration of ICU more than 7 days was one of the factors that contributed to the development of PED. This may related to direct relation between increases the time spent in ICU and that increase risk for factors that affected on the swallowing muscles. This finding is in line with Zuercher et al. $(2019)^{(60)}$, who found that prolonged ICU, and hospital length of stay, and increased morbidity and mortality associated with the presence of dysphagia. Also, Brodsky et al. (2017) ${ }^{(59)}$ who found that the patients with a longer ICU length of stay have slower recovery from dysphagia symptoms and should be carefully considered for swallowing assessment to help prevent complications related to dysphagia. In addition to Macht et al. $(2011)^{(20)}$ who found that there was a statistically significant difference between length of ICU stay and occurrence of dysphagia.

While there was no significance relation between gugging swallowing screen and level of consciousness as well as delirium occurrence post extubation. This may be related to that the studied patients should be alert and awake to perform this swallowing screen and follow command of the swallowing test. This finding is congruent to other studies ${ }^{(59,61)}$ which found that there was no statistically relation between conscious level as well as delirium and occurrence of dysphagia.

Regarding to medication related factor, the result of current study revealed that there was direct relation between occurrence of PED and corticosteroids medication. This may be related to over use of steroid medication may cause muscle wasting and damage the swallowing muscles. This finding is contrast with another study ${ }^{(61)}$ which found that there was no statistical relation between corticosteroids medication and dysphagia.

The result of this study showed that there are multiple factors associated with occurrence of PED for intubated critically ill patients. This factors include admission medical diagnosis, the current study showed that most of admission medical diagnosis associated with developed of PED were respiratory disease this may be due to the most common diagnosis admitted to ICU needs for immediate intubation are respiratory problem as respiratory failure, ARDS and COPD. This may be lead to dyssynchoranization between breathing and swallowing for patients had respiratory problem. This finding is supported by another study ${ }^{(18)}$ which found that respiratory failure was the most common indication for intubation and a respiratory diagnosis was the most common reason for hospital admission. This results are opposite with other studies ${ }^{(1,61)}$ which found that there was least of all intubated patients who present respiratory insufficiency could develop swallowing disorders. Also, Tsai et 
al. $(2016)^{(62)}$ who didn't found significant difference between admission medical diagnosis and PED occurrence.

Regarding co-morbidities as predictive factors, the results of current study showed that cardiac patients were vulnerable to PED. This may related to generalized weakness which lead to diminished cough strength, airway dry from mouth breathing, increase respiration rate during swallowing (pre swallowing apnea). This finding is supported by the finding of study done by Oliveira et al. $(2018)^{(29)}$ which indicate that systemic arterial hypertension make patients more vulnerable to mechanical damage due to arterial atherosclerotic alteration of the swallowing muscles. This finding is differed from another study ${ }^{(63)}$ which showed that there was no statistical significant difference between cardiovascular disorder as comorbidities and occurrence of PED.

Regarding gastric tube size, site and its duration, the result of current study revealed that there was direct relation between middle size of orogastric tube and duration spent with occurrence of PED. This may related to gastric tube is a foreign object that traverses the path way of entire food through invasion of pharynx and esophagus till reached to stomach, that have direct effect on swallowing muscles especially when increase diameters and increase duration of it. This finding is in line with other studies $^{(64,65)}$ which found that the duration of gastric tube is one of the risk factors for certain prognosis value for predicting dysphagia.

Gastric tube disorganized the pharyngeal contraction, narrow upper esophageal sphincter and then lead to slower swallowing velocity. Prolonged placement of the gastric tube appears to induce acidic gastroesophageal reflux and therefore contribute to pharyngeal mucosa damage. This finding is in contrast with another study ${ }^{(66)}$ which found that There were no significant differences between swallowing problem and presence or absence of either a small-bore or large-bore gastric tube.

Moreover, the present study shows that there was statistical significant between occurrence of PED and duration of mechanically ventilation, this may related to pathological changes that occur following extubation from M.V, patients often exhibit compensatory respiratory mechanics because of their altered lung volumes leading to abnormal breathe-swallow coordination which increased work of breathing and respiratory rates result in a shortening of the obligatory apneic period during swallowing. In addition, long duration of M.V lead to respiratory alterations, decreased glottic closure durations and unprotected airway while the bolus passes through the pharynx. This finding is supported with other studies $^{(23,67)}$ which found that there was independent association between the duration of mechanical ventilation and the severity of dysphagia supports the concept that endotracheal intubation maybe associated with some degree of neuromotor and sensory damage and poor coordination between breathing and swallowing, both of which may be exacerbated by recent mechanical ventilation.

\section{Conclusion}

Based on the findings of the current study, it can be concluded that the majority of the studied critically ill patients developed PED within the first 24 hours post extubation. The severity of PED varied between mild, moderate and severe. Most of the studied critically ill patients have been developed moderate dysphagia after 6 hours post extubation.

There were multiple iatrogenic factors that could contribute to PED during ICU stay for the studied patients. These factors include physiological changes related factors; gender, pathological related risk factors; diagnosis such as respiratory disease and co-morbidities; cardiac and renal disease. Additionally, clinical related factors; APACHEII and length of ICU stay and therapeutic related factors; duration of M.V, presence of endotracheal tube and gastric tube. The duration of mechanical ventilation was the most significant risk factors to PED after 24 hours according to binary logistic regression analysis.

\section{Recommendations}

- Critical care nurses should be continuously monitor the intubated critically ill patients who are risky to develop post extubation dysphagia.

- Put the Patients in upright position when starting his meals and remain upright 15$20 \mathrm{mn}$ after each meal.

- Follow Dietary modification recommendation; firstly, recommended thick diet after extubation such as thicker yogurt and boding followed by thin liquid like water after that hard or solid diet like bread.

- Follow swallowing maneuvers techniques as, use chin-tuck position when swallowing.

- Continuous in-serve training programs for CCNs in the ICUs according to important of uses Gugging assessment tool to assess PED. 
Table (1): Frequency distribution of studied critically ill patients in relation to the demographic data

\begin{tabular}{||c|c|c|}
\hline \multirow{2}{*}{ Data } & \multicolumn{2}{|c|}{ Studied patients (n=50) } \\
\cline { 2 - 3 } & No. & \% \\
\hline Age (years) & 5 & 10.0 \\
$18-30$ & 7 & 14.0 \\
$31-40$ & 4 & 8.0 \\
$41-50$ & 34 & 68.0 \\
$51-60$ & & \\
Sex & 32 & 64.0 \\
Male & 18 & 36.0 \\
Female & \multicolumn{2}{|c|}{} \\
\hline
\end{tabular}

Table (2): Frequency distribution of studied critically ill patients according to occurrence of dysphagia at different time intervals

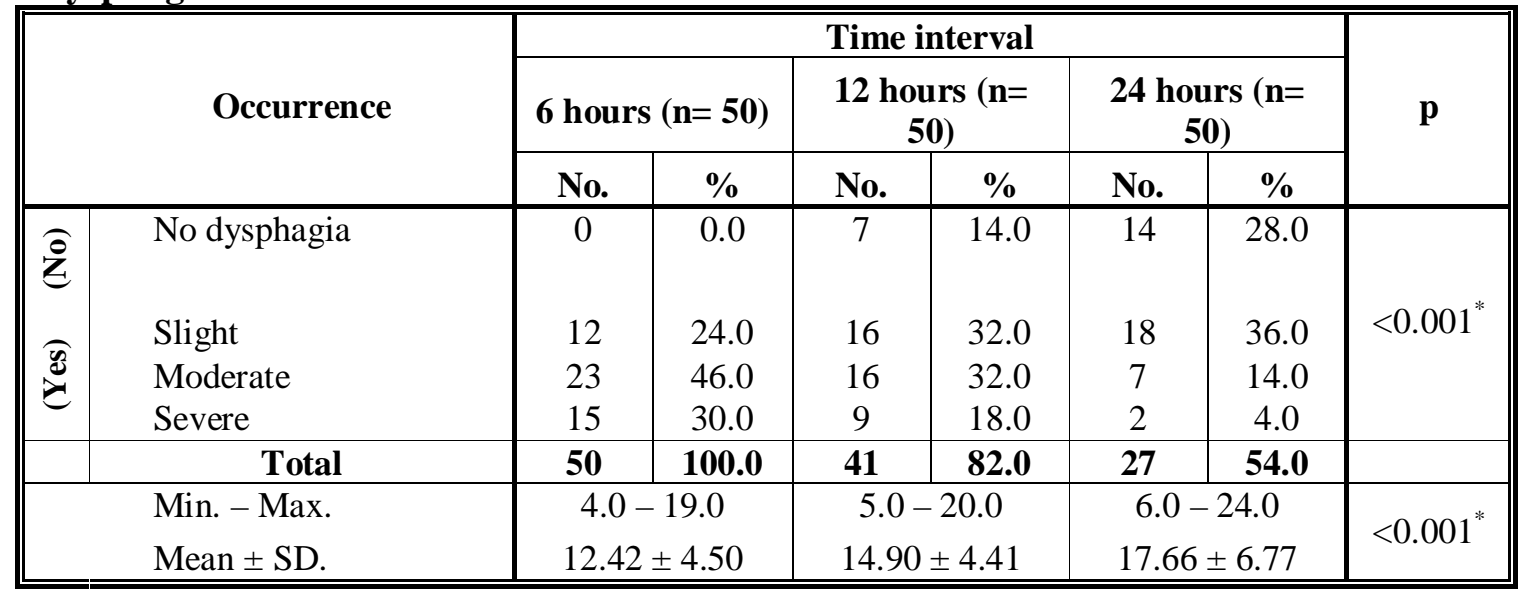

p: $p$ value for Friedman test for comparing between the three different parodies

*: Statistically significant at $p \leq 0.05$

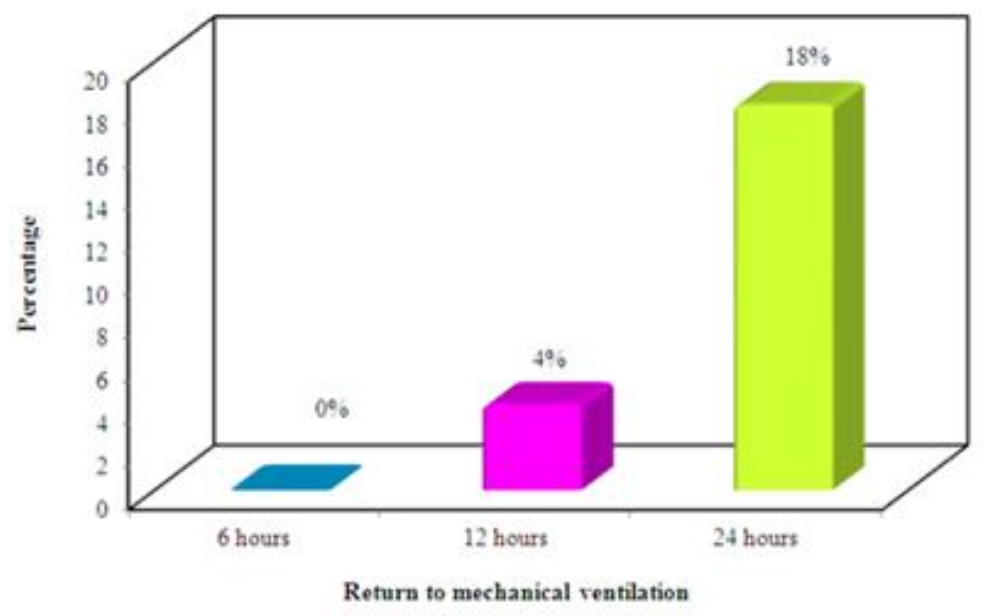

Figure (1): Frequency distribution of studied critically ill patients according to return to mechanical ventilation during the first $24 \mathrm{hrs}$ 
Table (3): Distribution of the studied critically ill patients according to clinical data

\begin{tabular}{|c|c|c|}
\hline \multirow{2}{*}{ Clinical data } & \multicolumn{2}{|c|}{ Studied patients $(\mathrm{n}=50)$} \\
\hline & No. & $\%$ \\
\hline $\begin{array}{l}\text { APACHE II score on admission } \\
\text { Min. - Max. } \\
\text { Mean } \pm \text { SD. }\end{array}$ & \multicolumn{2}{|c|}{$\begin{array}{c}9.0-38.0 \\
22.58 \pm 7.12\end{array}$} \\
\hline $\begin{array}{l}\text { CAM-ICU score post extubation } \\
\text { Dellirum } \\
\text { No Dellirum }\end{array}$ & $\begin{array}{c}0 \\
50\end{array}$ & $\begin{array}{c}0.0 \\
100.0\end{array}$ \\
\hline $\begin{array}{l}\text { LOC using (GCS) after extubation } \\
\text { Conscious } \\
\text { Semi conscious } \\
\text { Unconscious } \\
\end{array}$ & $\begin{array}{c}50 \\
0 \\
0\end{array}$ & $\begin{array}{c}100.0 \\
0.0 \\
0.0\end{array}$ \\
\hline $\begin{array}{l}\text { Length of ICU stay } \\
\quad<7 \\
\quad 7-14 \\
>14\end{array}$ & $\begin{array}{c}8 \\
24 \\
18\end{array}$ & $\begin{array}{l}16.0 \\
48.0 \\
36.0\end{array}$ \\
\hline $\begin{array}{l}\text { Min. - Max. } \\
\text { Mean } \pm \text { SD. }\end{array}$ & \multicolumn{2}{|c|}{$\begin{array}{c}3.0-75.0 \\
16.82 \pm 14.56 \\
\end{array}$} \\
\hline
\end{tabular}

Table (4): Relation between demographic data to gagging swallowing screen within first 24 hours for the studied critically ill patients

\begin{tabular}{|c|c|c|c|c|c|c|}
\hline \multirow{3}{*}{ Demographic data } & \multicolumn{4}{|c|}{$\begin{array}{c}\text { Gagging Swallowing Screen after } 24 \\
\text { hours }\end{array}$} & \multirow{3}{*}{$\begin{array}{l}\text { Test of } \\
\text { sig. }\end{array}$} & \multirow{3}{*}{$\mathbf{p}$} \\
\hline & \multicolumn{2}{|c|}{$\begin{array}{l}\text { No dysphagia } \\
\quad(n=14)\end{array}$} & \multicolumn{2}{|c|}{$\begin{array}{l}\text { Dysphagia } \\
(\mathbf{n}=\mathbf{3 6})\end{array}$} & & \\
\hline & No. & $\%$ & No. & $\%$ & & \\
\hline \multicolumn{7}{|l|}{ Age (years) } \\
\hline $18-30$ & 3 & 21.4 & 2 & 5.6 & \multirow{4}{*}{$\chi^{2}=4.724$} & \multirow{4}{*}{$\begin{array}{l}{ }^{\mathrm{MC}} \mathrm{p}= \\
0.145\end{array}$} \\
\hline $31-40$ & 3 & 21.4 & 4 & 11.1 & & \\
\hline $41-50$ & 0 & 0.0 & 4 & 11.1 & & \\
\hline $51-60$ & 8 & 57.1 & 26 & 72.2 & & \\
\hline \multicolumn{7}{|l|}{ Sex } \\
\hline Male & 5 & 35.7 & 27 & 75.0 & \multirow{2}{*}{$\chi^{2}=6.752^{*}$} & \multirow{2}{*}{$0.009^{*}$} \\
\hline Female & 9 & 64.3 & 9 & 25.0 & & \\
\hline
\end{tabular}


Table (5): Relation between clinical data to gagging swallowing screen within first 24 hours for the studied critically ill patients

\begin{tabular}{|c|c|c|c|c|c|c|}
\hline \multirow{3}{*}{ Clinical data } & \multicolumn{4}{|c|}{$\begin{array}{c}\text { Gagging Swallowing Screen within } \\
\text { first } 24 \text { hours }\end{array}$} & \multirow{3}{*}{$\begin{array}{l}\text { Test of } \\
\text { Sig. }\end{array}$} & \multirow{3}{*}{$\mathbf{p}$} \\
\hline & \multicolumn{2}{|c|}{$\begin{array}{l}\text { No dysphagia } \\
(\mathrm{n}=14)\end{array}$} & \multicolumn{2}{|c|}{$\begin{array}{c}\text { Dysphagia } \\
(\mathbf{n}=\mathbf{3 6})\end{array}$} & & \\
\hline & No. & $\%$ & No. & $\%$ & & \\
\hline $\begin{array}{l}\text { APACHE II score on } \\
\text { admission }\end{array}$ & \multicolumn{2}{|c|}{$19.07 \pm 8.09$} & \multicolumn{2}{|c|}{$23.94 \pm 6.31$} & $\mathrm{t}=2.263^{*}$ & $0.028^{*}$ \\
\hline \begin{tabular}{|l|} 
CAM-ICU score post \\
extubation \\
Dellirum \\
No Dellirum \\
\end{tabular} & $\begin{array}{c}0 \\
14 \\
\end{array}$ & $\begin{array}{c}0.0 \\
100.0\end{array}$ & $\begin{array}{c}0 \\
36 \\
\end{array}$ & $\begin{array}{c}0.0 \\
100.0\end{array}$ & - & - \\
\hline $\begin{array}{l}\text { LOC using (GCS) after } \\
\text { extubation } \\
\text { Conscious } \\
\text { Semi conscious } \\
\text { Unconscious }\end{array}$ & $\begin{array}{c}14 \\
0 \\
0\end{array}$ & $\begin{array}{c}100.0 \\
0.0 \\
0.0\end{array}$ & $\begin{array}{c}36 \\
0 \\
0\end{array}$ & $\begin{array}{c}100.0 \\
0.0 \\
0.0\end{array}$ & - & - \\
\hline $\begin{array}{l}\text { Length of ICU stay } \\
<7 \\
7-14 \\
>14 \\
\end{array}$ & $\begin{array}{l}6 \\
6 \\
2\end{array}$ & $\begin{array}{l}42.9 \\
42.9 \\
14.3\end{array}$ & $\begin{array}{c}2 \\
18 \\
16\end{array}$ & $\begin{array}{c}5.6 \\
50.0 \\
44.4\end{array}$ & $\begin{array}{c}\chi^{2}= \\
11.420^{*}\end{array}$ & $0.003^{*}$ \\
\hline $\begin{array}{l}\text { Min. - Max. } \\
\text { Mean } \pm \text { SD. } \\
\text { Median }\end{array}$ & $\begin{array}{r}3.0 \\
9.36\end{array}$ & $\begin{array}{l}20.0 \\
5.57 \\
\end{array}$ & $\begin{array}{r}5.0 \\
19.72\end{array}$ & $\begin{array}{l}75.0 \\
15.95 \\
0\end{array}$ & $\mathrm{t}=3.402^{*}$ & $0.001^{*}$ \\
\hline
\end{tabular}

Table (6): Binary Logistic regression for the parameters that affecting within first $24 \mathrm{hr}$ Dysphagia

\begin{tabular}{||l|c|c|c|c|c||}
\hline \multirow{2}{*}{$\mathbf{*}$} & \multirow{2}{*}{$\mathbf{N}$} & \multirow{2}{*}{$\mathbf{p}$} & \multirow{2}{*}{ OR } & \multicolumn{2}{|c|}{ 95\% C.I } \\
\cline { 5 - 6 } & & & & L.L & U.L \\
\hline Sex & 1.492 & 0.495 & 4.445 & 0.061 & 322.290 \\
\hline Respiratory disorder & 0.908 & 0.598 & 2.479 & 0.085 & 72.494 \\
\hline Cardiovascular disorder & -1.175 & 0.482 & 0.309 & 0.012 & 8.185 \\
\hline Length of ICU stay & 0.116 & 0.210 & 1.123 & 0.937 & 1.346 \\
\hline APACHE II score on admission & 0.201 & 0.084 & 1.223 & 0.973 & 1.537 \\
\hline Corticosteroid & 1.419 & 0.559 & 4.134 & 0.035 & 484.518 \\
\hline Gastric tube placement & -0.071 & 0.866 & 0.932 & 0.409 & 2.122 \\
\hline Gastric tube duration (day) & -0.387 & 0.704 & 0.679 & 0.092 & 4.986 \\
\hline Duration MV & 3.340 & $\mathbf{0 . 0 3 7}$ & 28.207 & 2.31 & 341.20 \\
\hline \hline
\end{tabular}

B: Unstandardized Coefficients

SE: standard Error

CI: Confidence interval

LL: Lower limit

UL: Upper Limit 


\section{References}

1. Skoretz SA, Flowers HL, Martino R. The incidence of dysphagia following endotracheal intubation: a systematic review. Chest 2010; 137(3): 665-73.

2. Rassameehiran S, Klomjit S, Mankongpaisarnrung C, Rakvit A. Postextubation Dysphagia. Proc (Bayl Univ Med Cent) 2015; 28(1): 18-20.

3. Gurjar M, Bhatia P. Endotracheal intubation. In: Misra UK, Darlong V, Agarwal V (eds). Manual of ICU Procedures. India: Jaypee Brothers Medical Publishers.; 2015, 17-29.

4. Smischney N, Kashyap R, Seisa M, Schroeder D, Diedrich D. Endotracheal Intubation Among the Critically Ill: Protocol for a Multicenter, Observational, Prospective Study. JMIR Res Protoc 2018; 7(12): e11101.

5. Boedeker B, Murray WB. Basic review of endotracheal intubation for providers at a mass casualty. The journal of education in perioperative medicine 2008; 10(1): E048.

6. Hyzy RC. Complications of the endotracheal tube following initial placement: Prevention and management in adult intensive care unit patients. 2019. Available at: https://www.uptodate.com/contents/complicat ions-of-the-endotracheal-tube-followinginitial-placement-prevention-andmanagement-in-adult-intensive-care-unitpatients. (Retrievd on: May, 2019).

7. Brodsky MB, Gonzalez-Fernandez M, Mendez-Tellez PA, Shanholtz C, Palmer JB, Needham DM. Factors associated with swallowing assessment after oral endotracheal intubation and mechanical ventilation for acute lung injury. Ann Am Thorac Soc 2014; 11(10): 1545-52.

8. Hanners J. Dysphagia post-extubation. The Southwest Respiratory and Critical Care Chronicles 2013; 1(3): 19-21.

9. Nordqvist C. What causes difficulty swallowing (dysphagia)?. 2017. Available at: https://www.medicalnewstoday.com/articles/ 177473.php. (Retrievd on: Oct, 2018).

10. Sue Eisenstadt E. Dysphagia and aspiration pneumonia in older adults. J Am Acad Nurse Pract 2010; 22(1): 17-22.

11. Alzheimer's queens land. Eating, drinking and swallowing difficulties in Dementia. AAQ Factsheet 10, 2017.

12. Paik NP. Dysphagia. 2018. Available at: https://emedicine.medscape.com/article/2212 409-overview. (Retrievd on: Oct, 2018).

13. Sassi FC, Medeiros GCd, Zambon LS, Zilberstein B, Andrade CRFd. Evaluation and classification of post-extubation dysphagia in critically ill patients. Revista do Colégio Brasileiro de Cirurgiões 2018; 45: e1687.
14. Ebihara S, Sekiya H, Miyagi M, Ebihara T, Okazaki T. Dysphagia, dystussia, and aspiration pneumonia in elderly people. J Thorac Dis 2016; 8(3): 632-9.

15. Zingarella AM. Psychosocial aspects of dysphagia following stroke. Master Thesis Thesis. School of Graduate Studies: Southern Connecticut State University, 2004.

16. Verdonschot R, Baijens LWJ, Vanbelle S, van de Kolk I, Kremer B, Leue C. Affective symptoms in patients with oropharyngeal dysphagia: A systematic review. J Psychosom Res 2017; 97: 102-10.

17. Ekberg O, Hamdy S, Woisard V, WuttgeHannig A, Ortega P. Social and psychological burden of dysphagia: its impact on diagnosis and treatment. Dysphagia 2002; 17(2): 13946.

18. Marvin S, Thibeault S, Ehlenbach WJ. Postextubation Dysphagia: Does Timing of Evaluation Matter? Dysphagia 2019; 34(2): 210-9.

19. Macht M, Wimbish T, Clark BJ, Benson AB, Burnham EL, Williams A, et al. Diagnosis and treatment of post-extubation dysphagia: results from a national survey. J Crit Care 2012; 27(6): 578-86.

20. Macht M, Wimbish T, Clark BJ, Benson AB, Burnham EL, Williams A, et al. Postextubation dysphagia is persistent and associated with poor outcomes in survivors of critical illness. Crit Care 2011; 15(5): R231.

21. Groher ME, Crary MA. Dysphagia: Clinical Management in Adults and Children. Maryland Heights, MO: Mosby Elsevier; 2010.

22. Walsh N. Clinical, economic costs of dysphagia are high, 2018.

23. Skoretz SA. Dysphagia Following Endotracheal Intubation: Frequency, Risk Factors and Characteristics. Ph.D Thesis Thesis: University of Toronto; 2015.

24. Guyomard V, Fulcher RA, Redmayne O, Metcalf AK, Potter JF, Myint PK. Effect of dysphasia and dysphagia on inpatient mortality and hospital length of stay: a database study. J Am Geriatr Soc 2009; 57(11): 2101-6.

25. Sporns PB, Muhle P, Hanning U, SuntrupKrueger S, Schwindt W, Eversmann J, et al. Atrophy of Swallowing Muscles Is Associated With Severity of Dysphagia and Age in Patients With Acute Stroke. J Am Med Dir Assoc 2017; 18(7): 635.

26. Razzaq HA, Sulaiman SA. Impact of Polypharmacy on Deglutition in Patients with Coronary and Cardiac Diseases. In: Speyer R, Bogaardt $H$ (eds). Seminars in Dysphagia. $2^{\text {nd }}$ 
ed. 2015, P.639-843. Intech. Available at: https://www.intechopen.com/books/seminarsin-dysphagia. (Retrievd on: Oct, 2018).

27. McFarland DH, Martin-Harris B, Fortin AJ, Humphries K, Hill E, Armeson K. Respiratory-swallowing coordination in normal subjects: Lung volume at swallowing initiation. Respir Physiol Neurobiol 2016; 234: 89-96.

28. Ghannouchi I, Speyer R, Doma K, Cordier R, Verin E. Swallowing function and chronic respiratory diseases: Systematic review. Respir Med 2016; 117: 54-64.

29. Oliveira ACM, Friche AAL, Salomao MS, Bougo GC, Vicente LCC. Predictive factors for oropharyngeal dysphagia after prolonged orotracheal intubation. Braz J Otorhinolaryngol 2018; 84(6): 722-8.

30. Falsetti P, Acciai C, Palilla R, Bosi M, Carpinteri F, Zingarelli A, et al. Oropharyngeal dysphagia after stroke: incidence, diagnosis, and clinical predictors in patients admitted to a neurorehabilitation unit. Journal of Stroke and Cerebrovascular Diseases 2009; 18(5): 329-35.

31. Pinto AR, Silva RG, Pinato L. Oropharyngeal swallowing in chronic renal failure. Codas 2016; 28(1): 71-6.

32. Arnold R, Issar T, Krishnan AV, Pussell BA. Neurological complications in chronic kidney disease. JRSM Cardiovasc Dis 2016; 5: 2048004016677687.

33. Brodsky MB, Gellar JE, Dinglas VD, Colantuoni E, Mendez-Tellez PA, Shanholtz $\mathrm{C}$, et al. Duration of oral endotracheal intubation is associated with dysphagia symptoms in acute lung injury patients. J Crit Care 2014; 29(4): 574-9.

34. Leder S. Effect of an orogastric feeding tube on swallowing success. 2010. Available at: https://www.asha.org/Events/convention/han douts/2010/2360-Leder-Steven/. (Retrievd on: Nov, 2018).

35. Balzer K. Drug-induced dysphagia. Int J MS Care 2000; 2(1): 40-50.

36. Swallow Study. Drug Interactions \& Sideeffects Chart. 2016. Available at: https://www.swallowstudy.com/wpcontent/uploads/2016/01/Medications-Sideeffects-Chart.pdf. (Retrievd on: Oct, 2018).

37. Mubeen R, Butt K. Knowledge of dysphagia, it's screening among nurses and awareness of role of speech and language pathologist in dysphagia. Riphah College of Rehabilitation Sciences 2012; 1:1-6.

38. Lees L, Sharpe L, Edwards A. Nurse-led dysphagia screening in acute stroke patients. Nurs Stand 2006; 21(6): 35-42.
39. Fattori B, Giusti P, Mancini V, Grosso M, Barillari MR, Bastiani L, et al. Comparison between videofluoroscopy, fiberoptic endoscopy and scintigraphy for diagnosis of oro-pharyngeal dysphagia. Acta otorhinolaryngologica Italica 2016; 36(5): 395-402.

40. See KC, Peng SY, Phua J, Sum CL, Concepcion J. Nurse-performed screening for postextubation dysphagia: a retrospective cohort study in critically ill medical patients. Crit Care 2016; 20(1): 326.

41. Batty S. Communication, swallowing and feeding in the intensive care unit patient. Nurs Crit Care 2009; 14(4): 175-9.

42. Werner $H$. The benefits of the dysphagia clinical nurse specialist role. The Journal of neuroscience nursing 2005; 37(4): 212-5.

43. Albini RM, Soares VM, Wolf AE, Gonçalves CG. Knowledge of nursing professionals about the care to dysphagic patients in intensive care units. Revista CEFAC 2013; 15: 1512-24.

44. Rhoda A, Pickel-Voight A. Knowledge of nurses regarding dysphagia in patients post stroke in Namibia. Curationis 2015; 38(2): 1564.

45. Cichero JA, Heaton S, Bassett L. Triaging dysphagia: nurse screening for dysphagia in an acute hospital. J Clin Nurs 2009; 18(11): 1649-59.

46. Kolapo KO, Vento S. Stroke: a realistic approach to a growing problem in subSaharan Africa is urgently needed. Trop Med Int Health 2011; 16(6): 707-10.

47. Barnard SL. Nursing dysphagia screening for acute stroke patients in the emergency department. J Emerg Nurs 2011; 37(1): 64-7.

48. Ferguson ND, Cook DJ, Guyatt GH, Mehta S, Hand L, Austin P, et al. High-frequency oscillation in early acute respiratory distress syndrome. N Engl J Med 2013; 368(9): 795805.

49. Da Silva Ferreira AM, Pierdevara L, Ventura IM, Gracias AMB, Marques JMF, dos Reis MGM. The Gugging Swallowing Screen: A contribution to the cultural and linguistic validation for the Portuguese context. Revista de Enfermagem Referência 2018; 4(16): 8592.

50. Macht M, Wimbish T, Bodine C, Moss M. ICU-Acquired Swallowing Disorders. Critical Care Medicine 2013; 41(10): 2396-405.

51. Moraes DP, Sassi FC, Mangilli LD, Zilberstein B, de Andrade CR. Clinical prognostic indicators of dysphagia following prolonged orotracheal intubation in ICU patients. Crit Care 2013; 17(5): R243. 
52. Schröder J, Glahn J, Dziewas R. ICU-related dysphagia epidemiology, pathophysiology, diagnostics and treatment. ICU Management 2015; 15(3): 108-11.

53. Nizolek KN. Risk factors for dysphagia in critically-ill patients with prolonged orotracheal intubation. Ph.D Thesis Thesis: Graduate School of Arts and Sciences: Columbia University, 2014.

54. Lee JH, Lee KW, Kim SB, Lee SJ, Chun SM, Jung SM. The Functional Dysphagia Scale Is a Useful Tool for Predicting Aspiration Pneumonia in Patients With Parkinson Disease. Ann Rehabil Med 2016; 40(3): 4406.

55. Trapl M, Enderle P, Nowotny M, Teuschl Y, Matz K, Dachenhausen A, et al. Dysphagia bedside screening for acute-stroke patients: the Gugging Swallowing Screen. Stroke 2007; 38(11): 2948-52.

56. Christensen M, Trapl M. Development of a modified swallowing screening tool to manage post-extubation dysphagia. Nurs Crit Care 2018; 23(2):102-7.

57. Park HS, Koo JH, Song SH. Association of Post-extubation Dysphagia With Tongue Weakness and Somatosensory Disturbance in Non-neurologic Critically Ill Patients. Ann Rehabil Med 2017; 41(6): 961-8.

58. Mouawad NJ, Ahluwalia GS. Dysphagia in the aging cardiovascular patient. J Thorac Dis 2017; 9(11): E1005-E8.

59. Brodsky MB, Huang M, Shanholtz C, Mendez-Tellez PA, Palmer JB, Colantuoni E, et al. Recovery from Dysphagia Symptoms after Oral Endotracheal Intubation in Acute Respiratory Distress Syndrome Survivors. A 5-Year Longitudinal Study. Ann Am Thorac Soc 2017; 14(3): 376-83.

60. Zuercher P, Moret CS, Dziewas R, Schefold JC. Dysphagia in the intensive care unit: epidemiology, mechanisms, and clinical management. Crit Care 2019; 23(1): 103.

61. Lugaro MC, Rios F, Lauria V, Jimenez S, Benito Mori L, Schoon P. Incidence of Postextubation Swallowing Disorders at the Critical Care Unit, by means of Fiberoptic Evaluation. Revista Americana de Medicina Respiratoria 2017; 17(3): 241-9.

62. Tsai M-H, Ku S-C, Wang T-G, Hsiao T-Y, Lee J-J, Chan D-C, et al. Swallowing dysfunction following endotracheal intubation: Age matters. Medicine 2016; 95(24): e3871-e.

63. Barker J, Martino R, Reichardt B, Hickey EJ, Ralph-Edwards A. Incidence and impact of dysphagia in patients receiving prolonged endotracheal intubation after cardiac surgery. Can J Surg 2009; 52(2): 119-24.
64. Zhou XD, Dong WH, Zhao $\mathrm{CH}$, Feng XF, Wen WW, Tu WY, et al. Risk scores for predicting dysphagia in critically ill patients after cardiac surgery. BMC Anesthesiol 2019; 19(1): 7.

65. Suslu N, Sefik Hosal A. Early oral feeding after total laryngectomy: Outcome of 602 patients in one cancer center. Auris Nasus Larynx 2016; 43(5): 546-50.

66. Fattal M, Suiter DM, Warner HL, Leder SB. Effect of presence/absence of a nasogastric tube in the same person on incidence of aspiration. Otolaryngol Head Neck Surg 2011; 145(5): 796-800.

67. Macht M, King CJ, Wimbish T, Clark BJ, Benson AB, Burnham EL, et al. Postextubation dysphagia is associated with longer hospitalization in survivors of critical illness with neurologic impairment. Crit Care 2013; 17(3): R119. 